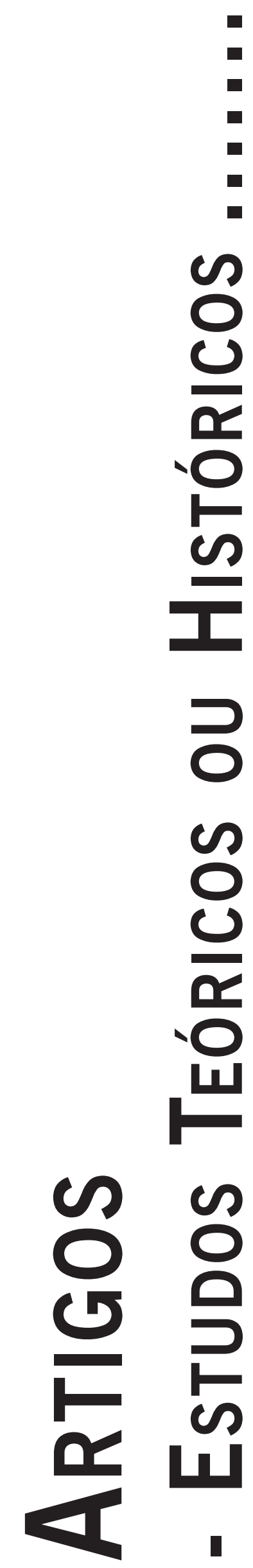




\title{
SUBJETIVIDADE E INDIVÍDUO: VIVÊNCIA DE TENSÃO
}

\author{
Subjectivity and Individual: Experience of Tension \\ Subjetividad y Individuo: Experiencia de Tensión
}

Carlos Roger Sales da Ponte

\begin{abstract}
Resumo: Trata-se de um breve estudo reflexivo acerca das categorias de subjetividade e Indivíduo, tal como meditadas pelo filósofo danês, Sören Kierkegaard. Longe de serem compreendidos como conceitos psicológicos ou sociológicos, estas categorias trazem, nelas mesmas, uma vivência de paradoxo, atravessado por uma fé apaixonada. Somente uma subjetividade experienciada no paradoxo absoluto (tarefa existencial do Indivíduo) pode assumir o devir cristão, ideia que atravessa toda a reflexão kierkegaardiana. Palavras-chave: Subjetividade; Indivíduo; Paradoxo; Fé; Devir.
\end{abstract}

\begin{abstract}
This is a reflective brief study of the categories of subjectivity and Individual, as meditated by danish philosopher Sören Kierkegaard. Far from being understood as psychological or sociological concepts, these categories bring, a paradox experience, crossed by a passionate faith. Only one experienced subjectivity in absolute paradox (existential task of Individual) can take the becoming Christian, an idea that runs through all of Kierkegaard's reflection.

Keywords: Subjectivity; Individual; Paradox; Faith; On becoming.

Resumen: Se trata de un estudio reflexivo breve de las categorías de la subjetividad y la individual, como meditado por el filósofo danés Søren Kierkegaard. Lejos de entenderse como conceptos psicológicos o sociológicos, estas categorías traen, de por sí una experiencia de paradoja, atravesado por una fe apasionada. Sólo una subjetividad con experiencia en la paradoja absoluta (tarea existencial del Individuo) puede asumir el devenir cristiano, una idea que corre a través de toda la reflexión de Kierkegaard.

Palabras-clave: Subjetividad; Individual; Paradox; Fe; Devenir cristiano.
\end{abstract}

\section{Introdução}

A subjetividade, em nossos dias, já se tornou uma palavra bem puída, dado o uso constante da mesma por diversos saberes concernentes ao humano. Não se irá aqui elencar todos os significados e usos possíveis do termo. Tarefa talvez enciclopédica ou de verbete para dicionários. Além do mais, seria maçante fazê-lo. De maior interesse, no entanto e como ponto de partida, a categoria da subjetividade com que o filósofo dinamarquês Sören Kierkegaard (1813-1855) trabalha, pode se nos afigurar, por vezes, como um quase um sinônimo de "interioridade psicológica". Mas não é só isso. Também pode ser encarada como uma postura em oposição à "objetividade" de pensar/viver em um modo especulativo; reflexiva, porém tributária de uma lógica sistemática racionalista e científica. Na compreensão de Kierkegaard, é claro, objetividade e especulação exalam os odores da filosofia de Hegel. Mas em que pensava Kierkegaard ao postular a categoria existencial da subjetividade? Tentar responder tal questão remete diretamente a outro termo comum na filosofia do danês: o Indivíduo. Há que se explicitar o primeiro termo para adentrar a este segundo. De todo modo, longe de serem compreendidos como conceitos "psicológicos" ou "sociológicos", estas categorias carregam, nelas mesmas, uma experiência ligada ao paradoxo e a uma fé apaixonada. De antemão, e apoiado por Kierkegaard, somente uma subjetividade experienciada no paradoxo absoluto (tarefa existencial do Indivíduo) pode assumir o devir cristão, tarefa ético-religiosa que atravessa toda a reflexão kierkegaardiana.

Em rápidas e provocativas palavras, tentemos descrever isso melhor tendo sempre em nosso horizonte o pensamento do danês.

\section{Subjetividade}

Para Kierkegaard, a verdade subjetiva, quando vivida (e não objetivada, excludente da relação de interioridade do e no humano), é verdade como paradoxo. É dessa relação com o humano existente que Kierkegaard quer chamar atenção. Encontrar-se numa dimensão subjetiva é vivenciar paradoxos. Uma procura por onde está a verdade já não faz sentido. Em Kierkegaard, não há mediação possível, posto que uma "síntese" equivaleria a ganhar um conceito fechado, limpo, redondo e claríssimo. No devir kierkegaardiano não há espaços para mediações e encerramentos; a verdade está em curso, posto que vivida na paixão que é "a mais alta expressão da subjetividade” (Kierkegaard, 1986a, p. 236). 
Kierkegaard não tolera a letargia dos filosofantes. Urge decidir, e o saber subjetivo é prenhe desta urgência, que não é sinônima de pressa. Urgência aqui é o que é imprescindível, necessário e que não pode esperar muito por considerações que fariam o humano recair na especulação vacilante bem ao gosto da tranquilidade e da paz quieta dos animais, não sendo então mais uma subjetividade apaixonada.

O humano vivente em sua paixão na interioridade liga-se ao como dos seus ditos. Este "como" é a abertura de sua vivência que se impede de fechar em verdades objetivas, exteriores a ele mesmo. Kierkegaard é enfático nas suas conclusões quando nos diz que

Objetivamente, não se interroga a não ser sobre o conteúdo do pensamento. Subjetivamente, não se interroga a não ser sobre sua interioridade. Em seu máximo, este como é a paixão do infinito e a paixão do infinito é a própria verdade. Mas a paixão do infinito é justamente a subjetividade e, assim, a subjetividade é a verdade. (Kierkegaard, 1986a, p. 238)

O que poderia ser esta subjetividade, senão um sinônimo de liberdade? E por quê? Porque se separa dos grilhões de um conforto que fariam do humano apenas mais um na massa da multidão, seguindo seus descaminhos confortáveis de rebanho. Ao contrário, o humano existente termina não podendo escapar de si e, em meio a toda a angústia de liberdade, toma a si mesmo em mãos, responsabilizando-se por sua verdade. Pode-se dizer que a subjetividade se apresenta como algo que traz redenção ao existente (Le Blanc, 2003). Esta "redenção" é o coroamento desta tensionada liberdade subjetiva. O que não significa uma espécie de "síntese".

A filosofia hegeliana (segundo o ponto de vista kierkegaardiano) tem a pretensão de tudo poder explicitar em termos de necessidade, direcionada a um fim. O reproche de Kierkegaard a esta filosofia é o seu caráter abstrato no tratamento com a realidade, deixando de lado a interioridade apaixonada. Repito: não há mediação, ou síntese; mas abertura e tensão postas no tempo contingente do humano. Lembremos: enquanto existentes, estamos em devir. Creio que foi um golpe de grande lucidez quando Kierkegaard, ao lembrar o caráter temporal que nosso existir, na subjetividade verdadeira (e não na objetividade falsa), é um esforço sem um ponto final, mas reanimado em diversas retomadas tensionadas, nunca findas.

O devir não é tão-somente uma constatação. É também um ato de fé de que a verdade se encontra no correr deste tempo contingente e trágico. Penso que para ilustrar este ponto de vista, recorro aqui a uma imagem bem conhecida feita por Kierkegaard: o que reza a Deus, mas sem paixão, e do pagão que reza a um ídolo, mas com toda a paixão e verdade infinitas. Kierkegaard pergunta: onde existe mais verdade aí? Aquele que vive o saber subjetivo não tem certeza de nada. Mesmo quando se dirige a Deus com toda a força de sua fé apaixonada, não possui garantias. Se as tivesse, assevera Kierkegaard, não necessitaria de fé. O filósofo, assim, toma partido do pagão que presta sua oração com fé.

A fé, em Kierkegaard, não é uma mera virtude teologal, nem é dispensada em um conceitual acabado e sistemático. Nem poderia. Mas o que é a fé para o pensador danês? E aqui, diferente de outras de suas obras pseudonímicas, quem aqui fala é o Magister Kierkegaard.

O Discurso Edificante, A expectativa da fé, foi escrito por Kierkegaard para ser o primeiro de uma série de pequenas obras assinadas por ele mesmo sem recorrer a pseudônimos. Essa produção, estritamente religiosa, estendeu-se até, aproximadamente, 1852. E o que se percebe como primeira impressão (e um pouco de imaginação) é a de um Kierkegaard de fala sóbria, porém acolhedora, típica de um tom pastoral, erguido em um púlpito, por sobre ouvintes atentos, a escutar seu sermão dominical. Mas ele mesmo declara ser o menos indicado a realizar sermões, pois, para isso, haveria de ter autoridade, coisa que não considera possuir. Prefere discursar para quem queira ouvir (Kierkegaard, 2001).

Kierkegaard atesta: fé é tarefa. E assim é preciso ter claro que a compreensão da fé está em apreender seu significado essencial, não como conceito aplicável a qualquer fato tal como uma lei humana que, espera-se, possa se adequar. O que está em questão, por princípio, é este desejar pela fé que aponta para a não-completude do humano; para seu modo de ser finito. Daí Kierkegaard lançar mão de diálogos no correr do texto, que são como que inquietações de quem procura um sentido a fim de realizar a fé tão almejada. Kierkegaard aponta caminhos possíveis, características e atributos que soam como experiência possível no sentido da fé. É preciso tomar a fé como para se chegar à fé (Kierkegaard, 2001). Este é outro jogo de vivência paradoxal.

Mesmo que se descarte a natureza objetal da fé, como pensar que ela possa ser possuída por mim e por muitos ao mesmo tempo? Kierkegaard responde que a fé é algo que o humano realiza; é uma experiência. Quanto a isso ele é bastante enfático ao dizer, nesta famosa passagem, sobre a possibilidade de posse da fé e de passá-la a outrem. Escreve ele que "uma pessoa pode fazer muitas coisas por outra, mas não pode dar-lhe fé” (Kierkegaard, 2001, p. 31).

Entretanto, se o humano não sabe o que é a fé, como e onde vai encontrá-la ou realizá-la? Embora Kierkegaard insista na necessidade da fé, ele menciona, em seus pequenos diálogos, as possíveis experiências das desventuras humanas que impõem dúvida e receio sobre a nossa própria existência. A fé é uma tarefa, já foi dito. Mas é sempre uma tarefa a ser recomeçada. Ela não é objeto de posse de uma vez por todas. Se assim fosse, possuiria um perfeito conceito fechado em si mesmo denotando um saber absoluto e se dissolveria enquanto experiência. Como se vai então à fé? Segundo Kierkegaard, como experiência, 
é algo continuamente gerada e adquirida (Kierkegaard, 2001). Só se tem dela experiência, em última instância, quem dá um salto. Um salto no escuro.

Kierkegaard afirma que a fé é uma expectativa. Expectar é o mesmo que esperar. No entanto, não é do "verde" da esperança que Kierkegaard fala. Nem mesmo de uma esperança romântica de coisas boas que seguramente vão ocorrer, bastando, é claro, "esperar” para que ocorram. Tal raciocínio, sabemos bem, promove que se recaia em um círculo vicioso que, mais do que girar sobre si mesmo, leva a muitos a adentrarem em um imobilismo, ou, no pior cenário, no desespero...

Kierkegaard não cessa de falar que a expectativa da fé é vitória. O sentido de "vitória" remete imediatamente ao caráter anterior de luta. O filósofo afirma que ninguém consegue ser mais forte que nós senão nós mesmos. Mas como vencer a nós mesmos? Ou, como perder de nós mesmos? Primeiramente, o si-mesmo de nós $\mathrm{Co}$ mo um outro é saber-se na condição de pecador; finito. A ânsia por completude é totalmente despropositada ao empreendimento da luta, sob pena de perder-se, desorientado e não sabendo ao certo onde está o bem que tanto almeja. Sabendo-se finito, o humano dialoga consigo em busca da fé. Assim, é a configuração de uma luta que jamais cessa, e isso aponta, mais uma vez, para a tarefa constante da fé; isto é, espera vivida a fim de que ela faça valer a vitória.

Essa fé só se espera em mira com o eterno (Kierkegaard, 2001). Embora o eterno dê a entender o seu oposto, o movimento como devir, este eterno aponta para o Absolutamente Outro, figura pouco mencionada neste Discurso. Ele lampeja. Kierkegaard apenas deixa subtendida a figura divina. Deste modo, no dizer de Kierkegaard, a fé é o órgão do sentido que capta o histórico (Kierkegaard, 1995, p.117s). Ter fé é ter sentido histórico: é experiência de enfrentamento contínuo de si como tarefa compreensiva e interpretativa. O enfrentamento aponta para o estranho, para este Deus que se fez humano como o eterno no tempo. Deus como o histórico é ao mesmo tempo expectativa e projeto a ser interpretado, pois surge para mim como negatividade que me escapa e também me envolve a ponto de jamais concluí-lo ou cercá-lo. O mesmo se pode dizer da fé, que em se lutando/expectando realiza-se como história da minha subjetividade, aqui compreendida como incerteza.

Voltando à subjetividade e sua paridade com a verdade, repetidas vezes Kierkegaard, vem nos lembrar, também, de que "a subjetividade é a não-verdade" (Kierkegaard, 1986a, p.241). Contradição? Não mesmo! Ele reafirma nossa condição de entes pecadores. E sobre este cúmulo de vivências plenas de tensões, escreve ele que

a subjetividade enquanto quer começar a tornar-se verdade, através de um processo de subjetivação, acha-se nesta situação difícil que ela é a não-verdade. Assim, o trabalho recua, isto é, perde em interioridade.
Longe de o caminho conduzir ao objetivo, o começo não faz mais do que mergulhar mais profundamente ainda na subjetividade. (Kierkegaard, 1986a, p.241)

E mais ainda, "se já era paradoxal que a verdade eterna se relacionasse com o sujeito existente, é agora absolutamente paradoxal que se relacione com um tal sujeito existente" (Kierkegaard, 1986a, p.241). Por outros termos, este "sujeito existente" é o humano pecador.

O humano se encontra na não-verdade. Ele é a não-verdade. Mas como o humano chega a ganhar essa consciência? Nas Migalhas Filosóficas, escrito pelo pseudônimo Johannes Clímacus, Kierkegaard diz que o humano não pode ser considerado ignorante, pois ele foi lembrado pelo mestre, isto é, Cristo. A pergunta pela verdade já é decorrência de um reconhecimento como estando na não-verdade. Se o humano não tem a condição de perceber a verdade em sua inteireza, não foi por causa de Deus, mas por culpa do próprio humano. Esse estado de culpa é o pecado. (Kierkegaard, 1995, p.35).

O pecado é a culpa. O desnível entre o humano e Deus, mesmo depois de adquirir a consciência do pecado e da verdade como subjetividade, ainda se mantém. Disso se conclui que esta falta não pode ser apagada por esta consciência nova. A consciência da não-verdade é uma condição da qual jamais se sai; é exatamente onde o humano se situa, ou melhor, ele mesmo é essa situação de cindido. Só assim o humano pode perguntar pela verdade e ir ao seu encalço: já estava na não-verdade, mas perguntava e se ocupava. Agora que ele sabe que é não-verdade, pode perguntar pela verdade. Verdade e não-verdade imbricam-se numa dialética irresolvível. Só a possibilidade aí aberta pelo não-ser se põe como tarefa. Vê-se perfeitamente o par dialético do desocultamento/ocultamento que será mais tarde aprofundado, tempos depois de Kierkegaard, por Heidegger, em sua obra Ser e Tempo. São lampejos e sombras desta tensão sem síntese.

Para vir-a-ser um autêntico existente dentro do devir cristão, e não apenas mais um na massa de gente, é preciso a consciência de ser finito e pecador. O existente é a prova viva desta dialética entre verdade e não-verdade; entre o eterno e o temporal em devir. A existência, em Kierkegaard, é uma impossibilidade. "Impossível” é o que não poderia ser ou acontecer em circunstância alguma. Disto se deduz que tal existência imersa nas tensões subjetivas acima descritas a partir da fala kierkegaardiana, seria de um inenarrável sofrimento que provavelmente poucos poderiam suportá-la. No entender de Kierkegaard, Cristo o viveu. Como não somos o Cristo, está ao nosso alcance a possibilidade de tornarmo-nos cristãos à sua imagem e semelhança subjetiva e existente.

Diferente de Sócrates, outro grande interlocutor constante na obra de Kierkegaard, que professava sua docta ignorantia, o existente sabe muito bem para onde vai: para a beira do abismo da "incerteza certa" chamada fé. Postando-se à beira, ele salta. E ainda aqui (parado- 
xalmente), ele é semelhante a Sócrates que dizia saber que nada sabia. Afinal, repitamos, não há garantias na fé. Somente uma subjetividade experienciada no cadinho do paradoxo absoluto pode navegar nas águas intranquilas do devir cristão, atravessado pela verdade e não-verdade, posto que nenhuma delas é posse do humano. Elas é que o possuem, o definem, o condenam, o salvam. E esta subjetividade toma forma, encarna-se em outra categoria kierkegaardiana (aqui apenas subtendida): o Indivíduo.

\section{Indivíduo}

De certo modo, foi dele que se falou até aqui, quando foi ressaltada a questão dos pseudônimos, e que agora se pretende sublinhar alguns aspectos em que o próprio Kierkegaard se deteve a fim de dizer com propriedade quem é este Indivíduo. Antes de adentrar nos meandros desta reflexão kierkegaardiana, é de interesse fazer algumas diferenciações terminológicas no sentido de mostrar de que categoria Kierkegaard não está falando.

Paula (2009), sobre o termo "Indivíduo", escreve que "este possui duas origens: em grego, se diz atomon e, na língua latina, individuum. Em ambos os idiomas, o significado aproxima-se de lago que possui uma unidade originária e singular” (p. 39). Dirigindo sua atenção à língua dinamarquesa, Paula (2009) aponta que

o tema do indivíduo, na obra kierkegaardiana, pode ser melhor iluminado através de três termos específicos do idioma dinamarquês: o primeiro deles é exemplar, que serve para designar um integrante da espécie humana; o segundo é individ, que equivale a pessoa, relacionando-se também ao meio social humano; já o terceiro, enkelte, está mais relacionado àquele indivíduo que se assume existencialmente. Em todos esses casos, a individualidade (individualitet) mostra-se superior aos indivíduos isolados. O pensamento kierkegaardiano diferencia o indivíduo da mera determinação animal. (p.140. Em itálicos no original)

Perante tal determinação de "individualidade" que se encontra numa posição superior diante de outros humanos, pode parecer incorrer em uma contradição que se pretenda circunscrever a noção de Indivíduo. Mas não há escolha tranquila na filosofia do danês. Incorre aqui a lembrança de que Wittgenstein afirmou certa vez, me conversas com seus colegas da Filosofia Analítica do Círculo de Viena, que tinha enorme respeito por aqueles que, não se calando, tentavam dizer o que, para ele, não poderia ser dito por que não haveria condições de dizer (que ele resume na conhecida última proposição do seu Tractatus: "Aquilo que não pode ser dito, deve calar- se”). Para o filósofo austríaco, quem a isto se dedica é alguém que se atira em um "salto", a fim de expressar um desejo de falar o que estaria para além da linguagem, atirando-se contra as grades de sua jaula. Lançar-se contra estas grades é tentar mostrar um esboço deste ente Individual que encontra seu sentido último na sua relação com Deus. Mais uma vez, os passos kierkegaardianos serão o guia.

Primeiramente devemos lembrar que ao humano é dada a condição de ser membro de uma espécie, onde ele poderia muito bem permanecer nesta condição se confundido com a "massa", o "rebanho" ou a "multidão". Todavia, ao humano é dada a possibilidade de refazer sua vida e tornar-se Indivíduo. Não que ele escolha existir de agora em diante, posto que já se encontre na posição prévia de ser-no-mundo (para utilizar uma expressão de Heidegger). Só precisa decidir-se diluir na multidão ou tornar-se singular, existente Individual. Diz nos Kierkegaard,

A multidão se compõe de indivíduos. Deve estar, pois, ao alcance de cada um tornar-se o que é: um indivíduo. Ninguém, ninguém em absoluto está excluído de tornar-se um indivíduo exceto aquele que se exclui de si mesmo, tornando-se multidão. (Kierkegaard, 1986b, p.169)

E se é de decisão, de escolhas que se fala, então é da liberdade que o humano precisa haver-se, pois existir autenticamente implica em pesar sempre as possibilidades e não se deixar levar pela massa, caminho mais fácil para ir levando a vida. Portanto, se a verdade do Indivíduo é uma verdade subjetiva, o caminho para compreendê-la é o da responsabilidade devidamente ponderada na interioridade subjetiva, onde vigem a verdade e a não-verdade. Apesar de que já foi apontado que, para Kierkegaard, a existência é um impossível, lá vem ele nos dizer que ela é, também, possibilidade de escolha. Eis aqui mais um par dialético desprovido de mediações ou resoluções. A intranquilidade, é claro, ainda vigora aqui.

Na dúvida, o humano deve lançar-se nos braços de Deus, amparado na incerteza da fé. Assim, as escolhas do Indivíduo (se Indivíduo, ele decidir tornar-se) serão permeadas pela angústia, posto que nada mude nas indeterminações da existência. Não é à toa que, segundo Bannour (1974, p.262), "o destino do Indivíduo é ser solitário”. Mas por que deveria ele ser solitário? Kierkegaard o confirma?

A resposta é positiva, pois Kierkegaard, quando se põe a escrever (seja em suas obras assinadas por ele mesmo ou por seus pseudônimos), ele o faz a todos e a cada um. Ele foi um solitário. O Indivíduo também é: não procura sua justificação com alguém ou com a multidão. Sua relação e justificação provêm unicamente de Deus. Se tudo se resume em tornar-se cristão, logo, a escuridão e a penumbra são parte deste mesmo percurso.

Ao escrever sobre o Indivíduo, Kierkegaard arrisca-se. Afinal, como falar publicamente desta categoria (posto que não chega a ser um conceito "fechado" e "pronto") 
tão existencialmente pertencedora a uma singularidade e intimidade, e ainda querer ser compreendido quando dela fala? A verdade do Indivíduo não pode ser senão uma verdade subjetiva. Como, pois, explicitá-la?

Ao escrever as Duas Notas sobre o Indivíduo em seu livro póstumo, Ponto de Vista Explicativo de Minha Obra como Escritor, Kierkegaard parece ter ainda diante de seus olhos os efeitos sociais da Primavera dos Povos (ocorrida em 1848) e que teve sua versão dinamarquesa. Deve ter sido isso que ele viu pela janela de sua casa: as multidões caminhando e gritando palavras de ordem pelas ruas de Copenhague, em prol de mudanças políticas no país. Estas notas são duas pequenas peças poético-incisivas inspiradas, também, pelo momento histórico danês de então.

Antes de iniciar suas Notas sobre o Indivíduo, e afirmando que "tudo é política”, Kierkegaard tem total consciência do quanto a mobilização das massas, neste plano temporal, mundano e secular, só se justifica na busca de uma vida materialmente melhor. Todavia, Kierkegaard não se ilude: a ação política que não leva em conta a escolha individual, particular de cada indivíduo em sua existência, tendo em vista a eternidade divina, pouco fará em mudar as formas de vida dos humanos. Embora o cristianismo seja uma "religião da prática” (Kierkegaard, 1986b, p.93), o ponto de vista kierkegaardiano afirma que a almejada busca pela igualdade humana, tão procurada pelas lutas políticas, é inútil já que "o religioso representa o verdadeiramente religioso" (Kierkegaard, 1986b, p.94). Por outros termos, a igualdade entre os homens só pode vigorar pela prática do amor ao próximo, posto que todos são criaturas de Deus. O político não conseguiria tal unidade.

Os humanos, segundo Kierkegaard, podem não perceber claramente, mas a sua temporalidade existencial e finita, almeja a eternidade. Mas os humanos nada querem saber do que do eterno pode advir. O enraizamento obstinado na dimensão temporal só faz crescer no humano, na forma de uma saudade e de um queixume que o aperreia em seu espírito disperso, a necessidade do eterno. Ele só não o sabe claramente. De certo modo, este raciocínio faz eco à tese platônica da Reminiscência.

Na Primeira das Duas Notas, Kierkegaard não parece fazer críticas que desqualifiquem a atividade política em si mesma, até mesmo reconhecendo sua necessidade nos assuntos terrenos. A ressalva que ele coloca é que não se pode tomar a política que se faz para o bem-estar geral como modelo para os assuntos ligados ao cristianismo: afinal, um número elevado de partidários de uma causa política, ou a sociedade civil organizada, podem reivindicar e conseguir algo com sua união. Todavia, fazer parte de um "monte de gente batizada" não é a garantia da bem-aventurança futura.

Assim, Kierkegaard fica o tempo inteiro contrapondo o Indivíduo que visa atingir "sua meta" sob os auspícios da divindade e aparentado a ela (Kierkegaard, 1986b, p. 97), com a "multidão", cuja a elevada quantidade numérica quer fazer crer poder corresponder à "verdade", qualquer que seja ela. Em momento algum, Kierkegaard fala de "grupo" ou "comunidade"; fala de "multidão", o que imediatamente lembra um aglomerado humano maleável e/ou conduzido por esta ou aquela ideologia.

Em Kierkegaard, o refúgio na multidão seria como um retorno ao paganismo. Entenda-se este termo colocado pelo filósofo como uma referência à maneira de viver dos antigos helenos nas póleis, permeadas pelo ideal democrático, regime ao qual Kierkegaard tinha suas reservas quando se queria tomar seu modelo político para o interior do cristianismo e para os assuntos ligados à divindade: viver democraticamente seria o livre uso da capacidade da razão que se torna inútil e escandalizada diante dos paradoxos da fé. O que importa, para além da temporalidade da multidão, é a eternidade onde o Indivíduo toma sua decisão e salta para atingir sua "meta".

Kierkegaard escreve claramente: "A multidão é a mentira". E o repete exaustivamente para salientar que nada em seu pensamento filosófico-religioso tem parte com aglomerações de gente, quer estejam elas organizadas ou não. Isso mostra com clareza como Kierkegaard, no fundo, era avesso a movimentos democráticos, simpatizando melhor com a monarquia. O filósofo prefere apontar suas acusações contra a multidão nervosa que tudo quer ditar. O Indivíduo é, acima de tudo, testemunha da verdade que "fala a cada um em particular, nas ruas e nos caminhos" (Kierkegaard, 1986b, p. 167).

O contraponto Indivíduo/Multidão é contundente. O indivíduo, para Kierkegaard, sempre se relaciona com a verdade. Por tal dedicação já é um mártir. Mesmo querendo partilhar com todos a sua relação com a Verdade, a fala do Indivíduo é dirigida a cada um em particular porque a decisão pelo eterno é de foro íntimo. Portanto, o poder secular, no entender de Kierkegaard, que se apoia na sociedade civil e a ela se dedica é perfeitamente justificado. No entanto, este poder da multidão se torna a "mentira" quando se arroga arbitrar em matéria espiritual e religiosa. É bem provável que esta crítica de Kierkegaard tivesse como alvo a Igreja Luterana dinamarquesa que tendia a confundir espiritualidade vivida com religiosidade de templos lotados, locus onde o Estado também exercia seu poder sobre a sociedade, uma vez que a esta Igreja estava submetida ao Estado, e seus pastores, funcionários remunerados pelo governo.

Kierkegaard pergunta: como o Estado poderia se imiscuir nos assuntos do Indivíduo com a verdade divina? Verdade esta em que Deus, o Absolutamente Outro, é a própria mensagem? Daí o filósofo reforçar a ideia do "Deus Pessoal" em consonância com o argumento de quem quiser se tornar o Indivíduo tem de tomar posse de si mesmo; reconhecer-se plenamente como devir e como tarefa inacabada na sua relação com a Verdade. Com certeza, imergir na multidão é bem mais fácil. Todavia, diluir-se deste modo, excluindo-se de si próprio, só faz 
do humano um número a mais entre as cabeças sem fim deste rebanho.

Na Segunda Nota, Kierkegaard é bem mais incisivo em delinear os contornos da categoria do Indivíduo. Ao mesmo tempo ele situa alguns sentidos possíveis dentro de sua obra como escritor eminentemente religioso. Para Kierkegaard, "a questão do Indivíduo é decisiva entre todas” (Kierkegaard, 1986b, p. 105). Kierkegaard afirma que, como escritor, cada obra assinada por um pseudônimo, de um modo ou de outro, apresentou a questão do Indivíduo. Trabalhando na baila de uma dialética sem síntese e sem superação, tornando mais tensa a dinâmica do devir cristão, o Indivíduo é aquele que pode se tornar "único" perante Deus. Estas significações são válidas, pois aquele que se torna o Indivíduo, nada possui de diferente ou especial: simplesmente foi uma questão de decisão em poder e querer ser. Daí certa ambiguidade conceitual: o Indivíduo só pode sê-lo por auxílio da Graça, porque tal existência é algo "no mais elevado grau" e que "ultrapassa as forças humanas" (Kierkegaard, 1986b, p. 109).

Passando em revista alguns sentidos a mais que o conceito de Indivíduo pode ter, Kierkegaard nos diz, primeiramente, que ele é a "categoria pela qual devem passar, sob o ponto de vista religioso, a época, a história, a humanidade" (Kierkegaard, 1986b, p. 109). Este raciocínio de Kierkegaard parece fazer alusão à mistura de filosofia, teologia e política de inspiração hegeliana, posto que um pouco mais à frente indique que esta categoria foi (e é) confrontada com "o Sistema" em todas as obras pseudonímicas. As revoltas populares de 1848 provavelmente foram gestadas bem antes; e como Kierkegaard tinha por hábito conversar com várias pessoas de vários segmentos sociais, é possível que tenha ouvido falar destas ideias revolucionárias e socialistas. Como Kierkegaard poderia concordar com a confluência entre a razão, o divino e a ação política?

Um segundo sentido é que o Indivíduo "é a categoria do espírito, do despertar do espírito, tão oposta quanto possível à política" (Kierkegaard, 1986b, p. 111): oposto à "multidão", o Indivíduo kierkegaardiano e sua existência é um contínuo sacrifício que o "despertar do espírito" faz surgir: uma nova forma de existir oposta à segurança de estar em um grupo ligado a assuntos temporais somente. Um terceiro sentido é que o Indivíduo é a "categoria cristã decisiva; e se-lo-á para o futuro do cristianismo" (Kierkegaard, 1986b, p. 111). Neste ponto Kierkegaard é enfático: só porque existe um elevado número de pessoas que se dizem cristãos, isso não significa que Deus as tenha abençoado com a Salvação, como se uma multidão pudesse tomar de assalto o cristianismo apenas pela quantidade de seus membros. Este comportamento revoltoso, segundo Kierkegaard, é fruto de uma reflexão desmedida que constrói razões pelas quais se poderiam tomar posse da Salvação. Kierkegaard acentua que o cristianismo verdadeiro é algo que "deve ser objeto de fé numa obediente submissão perante a majestade de Deus” e não algo que só encontraria acolhida se satisfizesse aos desejos e caprichos da "multidão". A compreensão e a existência no cristianismo são aspectos que só se constroem na relação individual e intransferível diante de Deus.

O quarto sentido elencado por Kierkegaard para a categoria do Indivíduo é de que com ela "a causa do cristianismo" ainda subsiste. Com este argumento o filósofo explica que, sem ela, o cristianismo transformar-se-ia em panteísmo que justificaria o dito popular que $a \mathrm{voz}$ do povo é a voz de Deus. Tal "justificativa” que encontra recepção total na multidão dos cristãos, em Kierkegaard não faz o menor sentido. O Indivíduo não tem sua voz em sintonia com Deus; sua sintonia está na submissão e obediência à vontade divina: ele escolhe resolutamente estar a sós consigo mesmo, mas junto a Deus. Existe uma relação aqui (não de um isomorfismo) totalmente assimétrica e heterogênea, posto que Deus é este Absolutamente Outro em relação a mim mesmo. A categoria do Indivíduo encontra sua força e destinação quando se quer mostrar o que é o autêntico devir cristão dentro da multidão da cristandade.

A filosofia kierkegaardiana do Indivíduo imputa uma escolha em despertar a imobilidade do espírito para a mobilidade do tornar-se espírito; isto é, tornar-se cristão que implica em sair do número da multidão para ser apenas um: uma exceção à regra massificante e inautêntica. Kierkegaard quer a autenticidade de escolha do humano, o qual, saindo da mera animalidade, "se assume existencialmente", construindo sua singularidade e individualidade para além dos humanos isolados entre si. Em Kierkegaard, Indivíduo, fé, angústia e decisão andam de braços dados.

\section{Considerações finais}

Como filósofo, Kierkegaard possui pretensões de uma visão de totalidade de mundo. Esta totalidade é a relação com Deus. Seu cristianismo nada tem de pacífico e suave. Não torna o "fardo leve": pesa-o mais ainda. Este modo de enxergar o mundo é um modo de perceber o humano em sua finitude fundamental, desde que tenha na fé seu amparo e refúgio, de certo modo.

O danês ainda nos aperreia: trata-se do Indivíduo viver uma vida que tenha sentido, vê-la em suas nuances existenciais e buscar a verdade subjetiva que valha a pena viver, para que não seja um mero transeunte destinado tão-somente a morrer um dia. A filosofia de Kierkegaard, a partir das categorias existenciais aqui apenas esboçadas em suas tensões, aponta para um pensar/viver mais rico, ainda que tenha algo de trágico. Não porque ele o quer, mas porque teimamos em não ver esta dimensão existencial que faria todo o sentido de uma vida inteira. É um devir nada tranquilo se matizado com as consequências compreensivas de si, do mundo e de Deus, advindo deste paradoxo absoluto que a divindade é e temperado pelo sabor agridoce da fé. 


\section{Referências}

Bannour, W. (1974). Kierkegaard. Em: François Châtelet (Org.). História da filosofia (Vol. 5: A filosofia e a história). Rio de Janeiro: Zahar Editores.

Kierkegaard, S. (1986a). Textos selecionados. Seleção e tradução por Ernani Reichmann. Curitiba: Editora Universidade Federal do Pará.

Kierkegaard, S. (1986b). Ponto de vista explicativo de minha obra como escritor. Lisboa: Edições 70.

Kierkegaard, S. (2001). Dois discursos edificantes de 1843. 2. ed. Rio de janeiro: Fábrica de livros.

Kierkegaard, S. (1995). Migalhas filosóficas, ou, um bocadinho de filosofia de João Clímacus. Petrópolis: Vozes.

Le Blanc, C. (2003). Kierkegaard. São Paulo: Estação Liberdade.

Paula, M.G. (2009). Indivíduo e comunidade na filosofia de Kierkegaard. São Paulo: Paulus.

Carlos Roger Sales da Ponte - Psicólogo; Mestre em Filosofia e Mestre em Psicologia pela Universidade Federal do Ceará (UFC); Professor de Fundamentos Epistemológicos e Históricos: Fenomenologia-Existencialismo e Humanismo do Curso de Psicologia da UFC/Campus Sobral; Membro do GEPFPF (Grupo de Estudos e Pesquisas em Fenomenologia e Psicologia Fenomenológica); e Doutorando em Filosofia pela UFC. Endereço institucional: Universidade Federal do Ceará (Campus Sobral). Av. Lúcia Sabóia, 215 - Centro - CEP: 62.010-830 - Sobral-CE - Brasil E-mail: jardimphilo@yahoo.com.br

Recebido em 26.10.2014

Primeira Decisão Editorial em 17.02.2017

Aceito em 12.05.2016 